\title{
CURRENT AND FUTURE HABITAT SUITABILITY MAP OF CUNNINGHAMIA KONISHII HAYATA UNDER CLIMATE CHANGE IN NORTHERN VIETNAM
}

\author{
Nguyen Thanh Tuan ${ }^{1 *}$, Ilaria Gliottone ${ }^{2 *}$, Mai Phuong Pham³ ${ }^{3}$ Dinh Duy Vu ${ }^{3,4}$ \\ ${ }^{1}$ Department of Forest Inventory and Planning, Faculty of Silviculture, Vietnam National \\ University of Forestry - Southern Campus, Dongnai, Vietnam \\ ${ }^{2}$ Department of Environmental Science and Policy, University of Milan, Milan, Italy \\ ${ }^{3}$ Institute of Tropical Ecology, Vietnam-Russia Tropical Centre, Hanoi, Vietnam. \\ ${ }^{4}$ Graduate University of Science and Technology (GUST), Vietnam Academy of Science and \\ Technology (VAST), 18 Hoang Quoc Viet, Cau Giay, Hanoi, Vietnam
}

*Corresponding author: Nguyen ThanhTuan,nttuan@vnuf2.edu.vn

Ilaria Gliottone, ilaria.gliottone@studenti.unimi.it

\begin{abstract}
.
Cunninghamia konishii Hayata is a rare and endangered plant species that plays a relevant role in ecological and commercial systems of natural forests in Vietnam. In this research, we evaluated the potential geographic distribution of C. konishii under current and future climatic conditions in Northern Vietnam using the ecological niche modelling approach based on the largest available database of occurrence records for this species. C. konishii is mainly distributed in the northern part of Vietnam at altitudes above $1000 \mathrm{~m}$ where the slopes range between 12 and 25 degrees, particularly in special-use and protected forest. The optimal distribution area of $\mathrm{C}$. konishii requires specific climatic conditions: an annual precipitation around $1200 \mathrm{~mm}$, precipitation of the warmest quarter ranging from 600 to $800 \mathrm{~mm}$, a precipitation seasonality of 90 to $100 \mathrm{~mm}$, an annual mean temperature ranging from $12^{\circ} \mathrm{C}$ to $19^{\circ} \mathrm{C}$, and a temperature seasonality ranging from 300 to 350. Additionally, the species requires specific soil groups: humic acrisols, ferralic acrisols, and yellow-red humic soils. Considering these requirements, the results of our research show that the suitable regions for the growth of C. konishii are found in the provinces of Ha Giang, Son La, Thanh Hoa and Nghe An, covering a total area of $1509.56 \mathrm{~km}^{2}$. However, analyzing the results under the Community Climate System Model version 4 (CCSM4) model, it is possible to observe that the area will decline to $504.39 \mathrm{~km}^{2}$ by 2090 according to $R C P 2.6$ scenario, to $406.25 \mathrm{~km}^{2}$ in the RCP 4.5 scenario, and to $47.62 \mathrm{~km}^{2}$ in the RCP 8.5 scenario. The findings of this present research may be applied to several additional studies such as identifying current and future locations to establish conservation areas for C. konishii.
\end{abstract}

Key words: Luanta-fir, niche model, climatic scenarios, habitat suitability, species distribution modelling

\section{INTRODUCTION}

Cunninghamia konishii Hayata (Luanta -fir) is distributed in Northern and central Taiwan, in China (Fujian), in Northern Laos and in Vietnam (Thi et al. 2016). In Vietnam, the species occurs naturally and it forms nearly pure or mixed populations with broadleaf trees, conifer tropical and subtropical moist forest in Ha Giang, Son La, Thanh Hoa, Nghe An (Thi et al. 2015). Luanta-fir is an economically valuable species and it has been exploited through time to obtain wood, oil and pharmaceuticals (Chung et al. 2004, 2009; Pham et al. 2010; Thi et al. 2015, 2016; Tran et al. 2015; Kodrul et al. 2018). During the last decades, unprecedented anthropogenic disturbances in tropical forests have caused severe degradation of the natural habitat of C. konishii (Chung et al. 2004).
In addition, this is has been shown that C.konishii Hayata has a low capacity of natural regeneration (Pham et al. 2010), therefore it is listed as critically endangered in the Vietnam Red Book, 2007 (Ban et al. 2007) as well as in the International Union for Conservation of Nature's Red List (IUCN Red List) urging for immediate protection measures (IUCN 2020).

One of the main objectives of today's forestry studies and management is the protection of biodiversity. Understanding the basic requirements of living habitats and distribution of each species is a top priority for conservation programs and action plans. Developing an understanding of the geographic distribution of tree species can provide important sources of information for conservation practices that seek 
to preserve the biodiversity of ecosystems (Dunckel et al. 2015). These pieces of information can also be used to determine suitable areas aiming to protect habitats through the management of natural reserves. Moreover, these management practices are important due to the fact that impacts of climate change on biodiversity are threatening the existence of natural species. Climate change has greatly influenced the large-scale distribution of species, and future climate change will also change the habitat, the range, and the distribution of many more species (Wang et al. 2018). Future geographical distribution of species, which would be strongly impacted by global warming and climate change, is uncertain. Therefore, determining whether climate change will affect the suitable habitat for $C$. konishii presents a critical problem linked to its ecological significance and to its economic value.

Species distribution modelling (SDM) is an instrument that can help us to understand more about the distribution of species (Tran et al. 2018). SDM has become a valuable tool for assessing habitat suitability and resource conservation to protect important plant species and to predict suitable cultivation regions (Kamyo \& Asanok 2020). SDM is widely applied to analyze potential distribution of endangered species and to predict changes of species distributions under different climate change scenarios (Urbina-Cardona et al. 2019). Species distribution modeling includes biophysical correlation model, climate element index method, generalized linear model (GLM), multivariate adaptive regression splines (MARS), genetic algorithm for rule-set production (GARP), maximum entropy (MaxEnt) and boosted regression trees (Sharma et al. 2018). MaxEnt was derived from maximum entropy theory, and it is one of the most used tools for species distribution modeling since the past decade. Compared with similar models, MaxEnt is widely preferred because it only needs current data of the species as input data, it develops accurate spatial environmental suitability maps for species, it assesses the importance of environmental variables for species distribution and it can make use of both continuous and discrete variables simultaneously as input data (Phillips et al. 2006; Kamyo and Asanok 2020).

In Vietnam, C. konishii has been studied so far through conventional field and laboratory approaches, mainly focusing on morphological characteristics, growth of seedling tree, genetic traits and chemical composition of the essential oil (Pham et al. 2007, 2009; Ngoc \& Quang 2012; Thi et al. 2015, 2016;
Ngoc \& Thi 2017; Thanh et al. 2017; Ngoc \& Thi 2018). The local distribution and some ecological characteristics of Luanta fir have been investigated in the Pu Hoat Nature Reserve of Vietnam (Thi et al. 2016). Until now, no attempt has been made to address the ecological requirements and the geographical distribution of $C$. konishii on a broader scale. In this study, we propose the use of maximum entropy techniques to predict the potential distribution of Luanta fir. The specific aims of this research are to (1) evaluate the geographical distribution of C. konishii, (2) to determine the relevant environmental factors influencing the species distribution, (3) to discuss the variations of suitable habitat under projected climate change conditions, and (4) to recommend conservation priority areas for future management actions. We believe that the results of this study may be used to determine suitable areas for C. konishii, and to protect the habitats through the management of natural reserves.

\section{Materials ANd Methods}

\section{Species occurrence and environmental data}

The occurrence locations of $C$. konishii were collected during a field survey across Northern Vietnam between 2018 and 2020 as the main goal of a project funded by Vietnam - Russia Tropical Centre, while the geographical coordinates were recorded using a Garmin GPS 76 handset (Fig. 1). The data were fil-

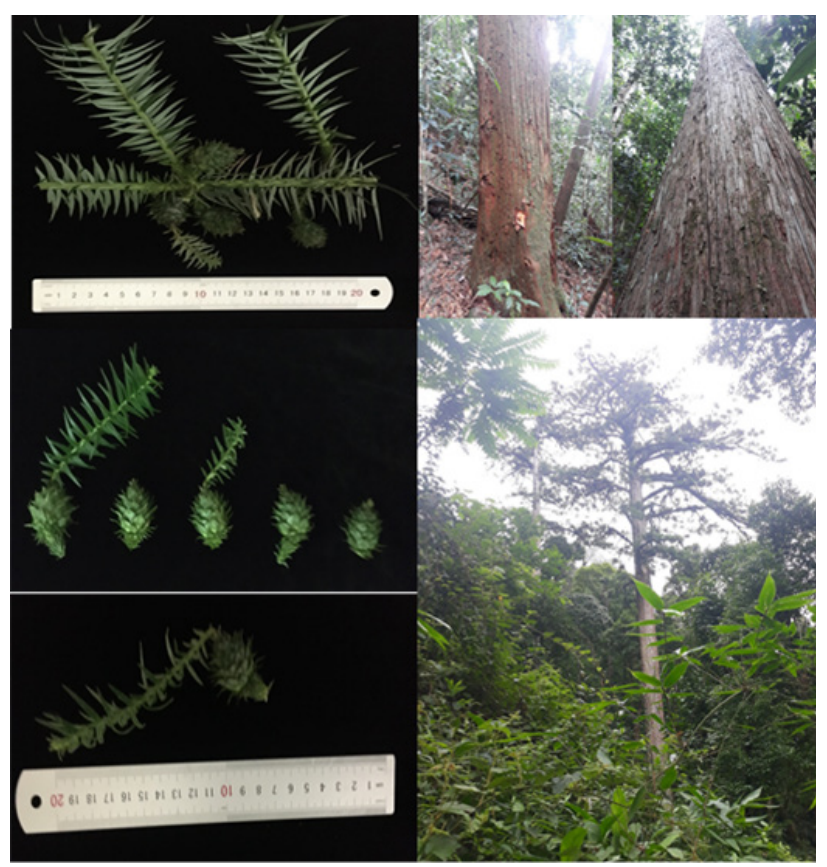

Figure 1: Cunninghamia konishii Hayata species. Photo credits: Mai Phuong Pham 
tered to remove any unreliable locality or uncertain species location which were found approximately less than $1 \mathrm{~km}$ away from each other, totaling 147 records across the four provinces (Ha Giang, Son La, Thanh Hoa, Nghe An) and resulting in a detailed distribution map (Fig 2). All records were imported into Microsoft Excel and saved as ".CSV" format. The latter was used as the input file for MaxEnt. Additionally, three types of variables were used in this study, including topographical variables (DEM, slope, and aspect, distance to river), bioclimatic variables, soil type, land-use, and vegetation data.

We used 19 bioclimatic variables provided by the World Climate Database (http://worldclim.org) with $1 \mathrm{~km}$ of spatial resolution which were measured on the basis of monthly meteorological records from 1970 to 2000 . The topographic variables, including elevation, slope and aspect, have the same resolution as the bioclimatic variables. The elevation layer was downloaded from the SRTM website (http://srtm.csi. cgiar.org). The slope and the aspect of the DEM data were derived using "spatial analysis" tools ArcGIS desktop and projected to WGS 1984 UTM zone 48 North. The distance from the river layer was extracted from the information of land use data, based on Euclidean Distance Tool in ArcGIS 10.2.

Land use data were retrieved from the 2016 National Forest Inventory of the Vietnam Administration of Forestry containing several major types of land uses, e.g., cropland, forest, grassland, value shrubland, urban fabric, water surfaces. Moreover, provided that tree cover is an important attribute for many plant and animal species, we retrieved it from GFW - Global Forest Watch database (http://globalforestwatch.org). In this research, the soil groups used for the purpose of this analysis were extracted from the National Soil Maps of Vietnam of Ministry of Natural Resources \& Environment. According to the Vietnam National ISO (TCVN 8409:2012) on agricultural production, land evaluation, and instruction for land use and planning, the area analyzed for this research includes 50 soil groups: yellow-brown soils, igneous rocks, yellow-red clay stones and metamorphic rocks, brow-yellow ferralic soils and alluvium soils, all featuring the same resolution as the previously mentioned environmental variables.

For future climate scenarios we used the CCSM4 climate change modeling data under the Representative Concentration Pathway (RCP) 2.6-2050s, RCP 2.6-2070s, RCP 8.5-2050s and RCP 8.5-2070s scenarios released by the IPCC Assessment Report

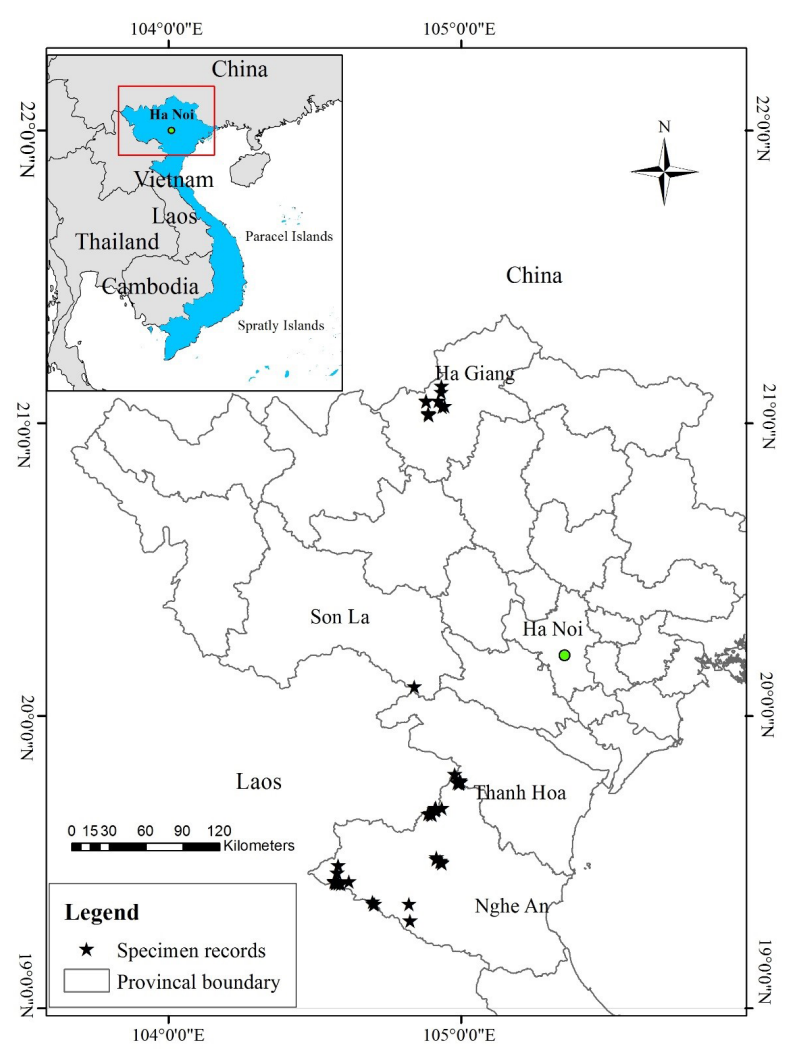

Figure 2: Distribution records of Cunninghamia konishii Hayata in Northern Vietnam

5 (AR5). Global Circulation Model CCSM4 was selected because it had been previously used to predict climate change impacts in Vietnam (Lima-Ribeiro 2015, Thuc et al. 2016). We used the same soil and vegetation data to run the analysis for future climate change scenarios.

\section{Data Processing}

The environmental parameters were rescaled on 30 " grid (with cell size: $1 \mathrm{~km}$ ) identical to the one of the bioclimatic data set. We used Spearman's rank correlation to examine the cross-correlation and we removed highly correlated bioclimatic factors (Pearson's $|r|>0.9$ ) to avoid multicollinearity of variables. The bioclimatic variables used to run the models are the following: average annual temperature (Bio1), Mean diurnal range (Bio2), Temperature Seasonality (Bio4), Temperature Annual Range (Bio7), Annual precipitation (Bio12) precipitation of driest month (Bio14), Precipitation Seasonality (Bio15) and Precipitation of the warmest quarter (Bio18) (Fig.S.1). In addition, topography, soil and land use factors were used for further analysis and modelling (Table $1)$. 
Table 1: Environmental predictors used for modelling the habitat suitability of Cunninghamia konishii Hayata

\begin{tabular}{|c|c|c|c|l|c|}
\hline Category & Environmental predictors & Code & Unit & Data Scale & Range value \\
& & & & & \\
\hline Topography & Aspect & ASP & Degree & Continuous & $0-360$ \\
\hline & Slope & SLO & Degree & Continuous & $0-34$ \\
\hline & Elevation & ELEV & meter & Continuous & $0-2730$ \\
\hline & Distance to river & RIVER & meter & Continuous & $0-100000$ \\
\hline Soil & Soil type & SOIL & & Categorical & 50 classes \\
\hline Land use & Forest cover & TREE & Percent & Continuous & $0-100$ \\
\hline & Land use type & LAND & & Categorical & 48 classes \\
\hline Climate & Annual Mean Temperature & Biol & Celsius degree & Continuous & $11.44-24.63$ \\
\hline & Mean Diurnal Temperature Range & Bio2 & Celsius degree & Continuous & $5.3-9.55$ \\
\hline & Temperature Seasonality & Bio4 & & Continuous & $285.32-501.47$ \\
\hline & Temperature Annual Range & Bio7 & Celsius degree & Continuous & $16.4-21.1$ \\
\hline & Annual Precipitation & Bio12 & Millimeter & Continuous & $1178-2335$ \\
\hline & Precipitation of the Driest Month & Bio14 & Millimeter & Continuous & $2-38$ \\
\hline & Precipitation Seasonality & Bio15 & & Continuous & $78.27-107.18$ \\
\hline & Precipitation of warmest quarter & Bio18 & Millimeter & Continuous & $398-1379$ \\
\hline
\end{tabular}

Current and future distribution of Luanta fir was produced with the use of the maximum entropy model in MaxEnt 3.3 software (Phillips et al. 2006). The final potential species distribution is shown on a map where the pixels represent the environmental suitability levels, and the values range from 0 (not suitable) to 1 (highly suitable) in an ASCII file (*.asc). The suitability level was subsequently divided into four classes of potential habitats, including: high potential $(>0.6)$, moderate potential $(0.4-0.6)$, low potential $(0.2-0.4)$, and not potential $(<0.2)$ (Zhang et al. 2018).

The area under the response curve (AUC) was used under application of the receiver operating characteristic (ROC) model to determine the precision of the species potential distribution model. The AUC value ranges from 0 to 1 , where AUC value $>0.7$ is adequate; $>0.8$ means good; and $>0.9$ indicates excellent performance (Yang et al. 2020).

Finally, we used SDM toolbox 2.0 (Brown, 2014) to determine the effects of climate change on the geographic distribution of Luanta fir for the years 2050 and 2070.

\section{Results AND Discussion}

\section{Evaluations of the model and its importance under current climatic condition}

According to the theory, an AUC scoring higher than 0.5 means that the model performs better than a random estimate. Thus, the obtained 0.987 AUC value proved the sensitivity of the model (Fig S.2).
These results showed that the performance of the model was very good and appropriate to evaluate the performance of a niche model, given that it exceeded a value of 0.75 (Elith et al. 2006). Therefore, the current distribution of $C$. konishii, that is characterized by the selected variables, is excellent. The MaxEnt Jackknife tests show the relative contribution of each predictive variable for $C$. konishii distribution model (Fig.S.3). The Jackknife test results showed that three environmental variables affected the species distribution the most, and they could be listed in order from the most to the least effective as it follows: land elevation (ELEV, 28.5\%), land use (LAND, 16.2\%), forest cover (TREE, 16\%), soil group (SOIL, 9.2\%), slope (SLO, 8.9\%), temperature annual range (BIO7, $7.2 \%$ ), and temperature seasonality (Bio4, 4.4\%). Considering the permutation importance, the elevation variable had the highest impact on the habitat model, and it contributed for $19.3 \%$, while forest cover, slope, annual mean temperature (Biol) and land use respectively contributed for $17.8 \%, 11.3 \%$, $10.9 \%$ and $10.1 \%$.

The response curves of the fifteen contributors for the C. konishii distribution are shown from Figure.S.3 to Figure.S.7. Each response curve depicts the relationship between each environmental variable and the logistic probability of presence. According to the response curves of topography variables, the most suitable elevations were above $1000 \mathrm{~m}$ and no reduction in suitability was found at higher elevations, whereas the suitable slopes were above 12 degrees with an optimum at about 25 degrees, and 
the suitable aspect ranged from 0 to 50 degrees of north and northeast. The curves of suitable habitats have increased with the increasing distance from the river, and they have reached the optimum at distance above $80 \mathrm{~km}$ (Fig.S.4). These results are relevant if compared to previous findings showing that most of C. konishii are located at $1120-1385 \mathrm{~m}$, north-facing slope ranging from 15 to 25 degrees in the Pu Huong Nature Reserve, in the Nghe An province of Vietnam (Thanh et al. 2017). While Thi et al. (2016) showed that most of $C$. konishii is found at altitudes ranging from $1180 \mathrm{~m}$ to $2320 \mathrm{~m}$, on high slopes from 35 - 45 degrees in the Pu Hoat Nature Reserve, in the Nghe An province of Vietnam. Moreover, the high altitude from $1200 \mathrm{~m}$ to $2700 \mathrm{~m}$ shows the good phenotype performance for the growth of $C$. konishii in Taiwan (Chung et al. 2004, Chung et al. 2009).

Regarding the temperature variables, we obtained the thresholds (existence probability above 0.4 ) for the main bioclimatic parameters. The ranges of environmental suitability with respect to the bioclimatic variables are shown below: Annual mean temperature (Bio1) ranged from $12^{\circ} \mathrm{C}$ to $19^{\circ} \mathrm{C}$; Mean diurnal temperature (Bio2) ranged from $7-9^{\circ} \mathrm{C}$; temperature seasonality (Bio4) ranged from 300 to 350; temperature annual range (Bio7) ranged from 16$17.5^{\circ} \mathrm{C}$. Additionally, the probability presence of $C$. konishii tends to decrease with the increase of Bio1, Bio4 and Bio7 (Fig S.5). Based on the precipitation variables, we elaborated the graphic suitability (Fig S.6) which was found to be related to: the annual precipitation (Bio12), the precipitation of the driest month (Bio14) which are respectively below 1200 $\mathrm{mm}$ and $5 \mathrm{~mm}$. While the suitability decrease related to: precipitation seasonality (Bio15) ranging from 90 to $100 \mathrm{~mm}$, and to the precipitation of the warmest quarter (Bio18) ranging from 600 to $800 \mathrm{~mm}$.

The tolerance of a particular range of temperatures and the precipitation are among the most important features used to explain the latitudinal distribution of a species. Especially, cold tolerance, growth-season temperatures, and available water supply are the main environmental indexes that influence the distribution of alpine vegetation (Woodwand 1987). C. konishii generally grows in tropical monsoon climate at submontane elevations with a mean annual temperature of $15-18^{\circ} \mathrm{C}$, and $4-6^{\circ} \mathrm{C}$ during cold months, a mean annual precipitation around $1800 \mathrm{~mm}$, and dry periods of 0-3 months (Pham et al. 2010). Variations in temperature affected growth, flower bud differentiation, seed dormancy and germination of C. konishii (Ngoc \& Thi 2018). Furthermore, the flower pollination period generally takes place from January to March, while seed maturity occurs from January to April of the following year (Loc et al. 2017). The seeds can germinate in a suitable environment when they fall to the ground. Adverse meteorological events during flowering from January to March, such as low temperature, can cause severe freezing injuries to flower buds. Moreover, low and high temperature, drought, and waterlogging during the young fruit-growing period will cause fruit drop. The above-mentioned evidence revealed that temperature and sufficient water are required for the regular growth and reproduction of the plant. Thus, the environmental variables that we used are efficient and reliable to predict a suitable habitat distribution map for this target species. Previous research has shown that the 19 bioclimatic variables are useful and widely used for species distribution model (Guo et al. 2018), and contrary to these findings, in this study we could not prove that the dominant bioclimatic variables describe the habitat requirements of $C$. konishii. The results that we obtained from the maximum entropy modeling demonstrated that elevation played a critical role in shaping the distribution, compared to climatic (temperature, precipitation) factors considered in this study.

Following, land use, forest cover and soil variables showed to be consistent with previous studies suggesting that elevation was one of the most important environmental variables determining plant distribution such as Dipterocarpus alatus and Hopea odorata (Asanok et al. 2020, Kamyo \& Asanok 2020). On the one hand, topographical variables derived from DEM such as slope and aspect can show a positive correlation with the elevation variable (Evcin et al. 2019). Slope and aspect have played important roles in the microclimate of narrow-range species (Moustafa et al. 2001). One the other hand, changes in the condition of land surface (elevation, slope and aspect) lead to changes in soil properties (Badía et al. 2016, Guo et al. 2018), temperature (Revadekar et al. 2013), monthly precipitation, forest structure and composition (Smith 2008), which indirectly affect plant growth and are the main drivers for the survival and persistence of mountain plant species (Oke \& Thompson 2015).

Moreover, the species distribution was based on forest cover (Fig S.7). The suitable distribution area of the species reaches the optimal level when there is $100 \%$ forest cover. In the response curves of the 
Table 2: Predicted potential distribution areas for C. konishii under current climatic conditions

\begin{tabular}{|c|c|c|c|}
\hline Place & $\begin{array}{c}\text { Low potential } \\
\left(\mathrm{km}^{2}\right)\end{array}$ & $\begin{array}{c}\text { Moderate potential } \\
\left(\mathrm{km}^{2}\right)\end{array}$ & $\begin{array}{c}\text { High potential } \\
\left(\mathrm{km}^{2}\right)\end{array}$ \\
\hline Ha Giang & 343.33 & 77.85 & 10.9 \\
\hline Nghe An & 574.55 & 266.26 & 109.77 \\
\hline Son La & 65.4 & 0.78 & 0 \\
\hline Thanh Hoa & 52.94 & 7.79 & 0 \\
\hline Northern Vietnam & 1036.22 & 352.67 & 120.67 \\
\hline
\end{tabular}

land use type, variables show the highest occurrence probability in special-use forests and protected forests where we observed a high percentage of forest cover (Table S2). The probability presence in special-use forests and protection forests is more than 0.4 while when we consider others land use the probability presence is below 0.1 . Most of original forest of $C$. konishii have disappeared due to the persistent impacts and pressure of the rural population on old growth forest. Hence, nowadays, only few remaining individuals were found in primary forests or close to native areas: as previously mentioned, in protected forest or in special-use forest, e.g., Xuan Lien Nature Reserve, Pu Mat National Park, Pu Huong Nature Reserve, Tay Con Linh and Du Gia mountains in Vietnam (Pham et al. 2010).

Additionally, the response curve related to group of soils shows that $C$. konishii grows predominantly in the presence of four soil groups, including Humic Acrisols ( $0.73 \%$ of probability presence), humus yellow-red soil on granite $(0.63 \%$ of probability presence), Ferralic Acrisols ( $0.59 \%$ of probability presence) and humus yellow-red soil on shale $(0.42 \%$ of probability presence) (Table S3). The results lead to similar conclusion where Cunninghamia konishii grows on Ferralic Acrisols-(Xfa) and Humic Acrisols-(Xha) in the Pu Hoat Nature Reserve, in the Nghe An province (Thi et al. 2016).

\section{Current potential distribution of $C$. konishii}

The results of the simulation of $C$. konishii ecological suitability area are shown in Figure 3. The targeted area was $120.67 \mathrm{~km}^{2}$ high, $352.67 \mathrm{~km}^{2}$ moderate and $1036.22 \mathrm{~km}^{2}$ low. Suitability areas for species are scattered in the provinces of Ha Giang, Son La, Thanh Hoa and Nghe An. Furthermore, the high potential suitable area of $C$. konishii is concentrated in small areas of the two provinces of Ha Giang and Nghe An, covering a total area of $10.9 \mathrm{~km}^{2}$ and $109.77 \mathrm{~km}^{2}$, respectively (Table 2). In this study, the results obtained with MaxEnt were noticeably similar to the real spatial distribution pattern of C. konishii forests. The habitat regions of $C$. konishii are small and show noncontinuous, patchy and mosaic distribution forms. The results are comparable with those of previous studies showing that in Vietnam, $C$. konishii individuals have been observed in Ha Giang, Thanh Hoa, Son La and Nghe An provinces, in dense subtropical forest, mixed with Fokienia hodginsii, Dacrydium pierrei, and Quercus bambusaefolia (Sau 1996). Additionally, the species under study is found in broadleaf forests and subtropical coniferous forests and where it is mainly concentrated along the border between Lao PDR and Vietnam. C. konishii matrix is usually mixed with species of families like Lauraceae, Clusiaceae, Elaeocarpaceae, Fagaceae, Theaceae, etc. (Thanh et al. 2017).

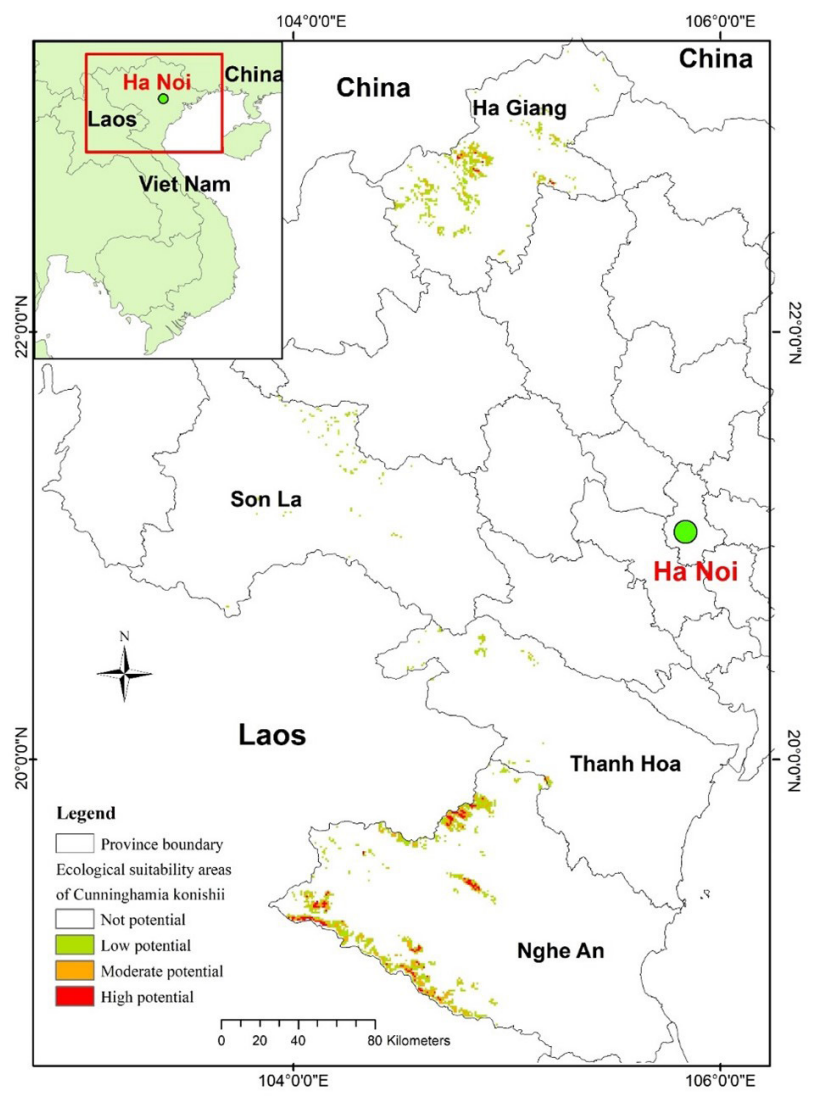

Figure 3: Potentially suitable climatic distribution of Cunninghamia konishii under current climate condition in Northern Vietnam 
Table 3: Changes in future geographic distribution (2050 and 2070) $\left(\mathrm{Km}^{2}\right)$ for C. Konishii due to climate scenario RCP $2.6,4.5$ and 8.5 .

\begin{tabular}{|l|c|c|c|c|c|c|}
\hline \multirow{2}{*}{\begin{tabular}{c}
\multirow{2}{*}{$\begin{array}{c}\text { Legend maps of } \\
\text { changes }\end{array}$} \\
\cline { 2 - 7 }
\end{tabular}} & \multicolumn{3}{|c|}{ Changes in geographical distribution by year and climate scenario $\left(\mathrm{km}^{2}\right)$} \\
\cline { 2 - 7 } & $\mathrm{RCP} 2.6$ & $\mathrm{RCP} 4.5$ & $\mathrm{RCP} 8.5$ & $\mathrm{RCP} 2.6$ & $\mathrm{RCP} 4.5$ & $\mathrm{RCP} 8.5$ \\
\hline Range expansion & 1.44 & 52.68 & 6.49 & 60.61 & 31.75 & 0 \\
\hline No occupancy & 140443.47 & 140392.24 & 140438.42 & 140384.30 & 140413.17 & 140444.92 \\
\hline No change & 107.52 & 319.66 & 119.06 & 443.78 & 374.50 & 47.62 \\
\hline Range contraction & 1402.04 & 1189.90 & 1390.50 & 1065.78 & 1135.06 & 1461.94 \\
\hline
\end{tabular}

\section{Model evaluations and the importance of the variables under different scenarios}

The AUC values for 2050s RCP 2.6, 2070s RCP 2.6, 2050s RCP 4.5, 2070s RCP 4.5, 2050s RCP 8.5, and 2070 s RCP 8.5 were respectively $0.989,0.987$, $0.987,0.988,0.989$ and 0.987 , indicating that the expected findings were very accurate. Based on the jackknife test of variable importance, the percentage contribution values of each ecological factor were obtained (Table S1). According to the Jackknife the test, for all the scenarios we analyzed, the distribution of $C$. konishii is mainly influenced by the elevation: the elevation variable contributed by $20.2 \%$ to $32.5 \%$ of importance in the distribution analysis. While other factors as slope, Bio4, land use, forest cover and soil group contributed below $20 \%$ in the prediction model.

\section{Future predictions and potential distributions of C. konishii}

For the years 2050 and 2070, the geographical distribution of $C$. konishii varied compared to the present one (Table 3 ). These results show that in the years 2050 and 2070 of both scenarios, the suitable habitat areas of $C$. konishii will decrease. Under present climatic conditions, Northern of Vietnam has an area of $\sim 1509.56 \mathrm{~km}^{2}$ where the $C$. konishii is possibly present; however, by 2050 , they are reduced to $\sim 108.96, \sim 372.34$ and $\sim 125.56 \mathrm{~km}^{2}$ under climatic scenarios RCP2.6, 4.5 and 8.5 respectively, while for 2070 under the same scenarios, the areas of possible presence are $\sim 504.39, \sim 406.25$ and $\sim 47.62 \mathrm{~km}^{2}$. Environmental suitability maps and potential distribution changes for C. konishii for 2050 and 2070 are shown in Figures 5 and 6 where it is possible to see that the suitability area mainly concentrates on the western part of the region, in the Nghe An and Thanh Hoa provinces.

This indicates that habitat losses of $C$. konishii in the future may reach a critical status due to envi- ronmental changes. In line with our studies, other researches showed that the geographical distributions of $C$. lanceolata and the total area of suitability will gradually decrease in the 2050s and 2070s (Li et al. 2020). Climate change, and especially global warming, will lead to the migration of plant distribution due to the changes in temperature and precipitation patterns in different regions.

The distribution centroid changes of environmental suitability of $C$. konishii for the future are shown in Figure 4. The results indicate that both the direction and the incidence of the changes differ among the climatic scenarios that were analyzed in

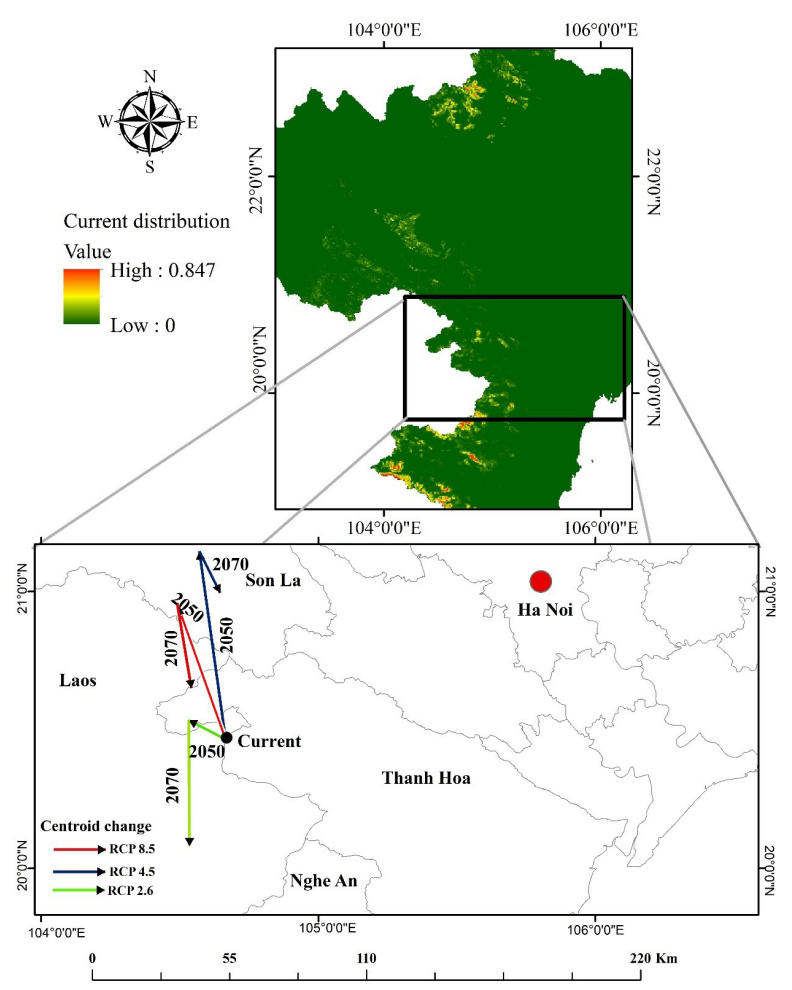

Figure 4: Changes of environmental suitability centroid for Cunninghamia konishii for the years 2050 and 2070 in Northern Vietnam. The green, orange and red vectors indicate the direction and magnitude of distribution changes under RCP scenarios 2.6, 4.5 and 8.5 respectively. 

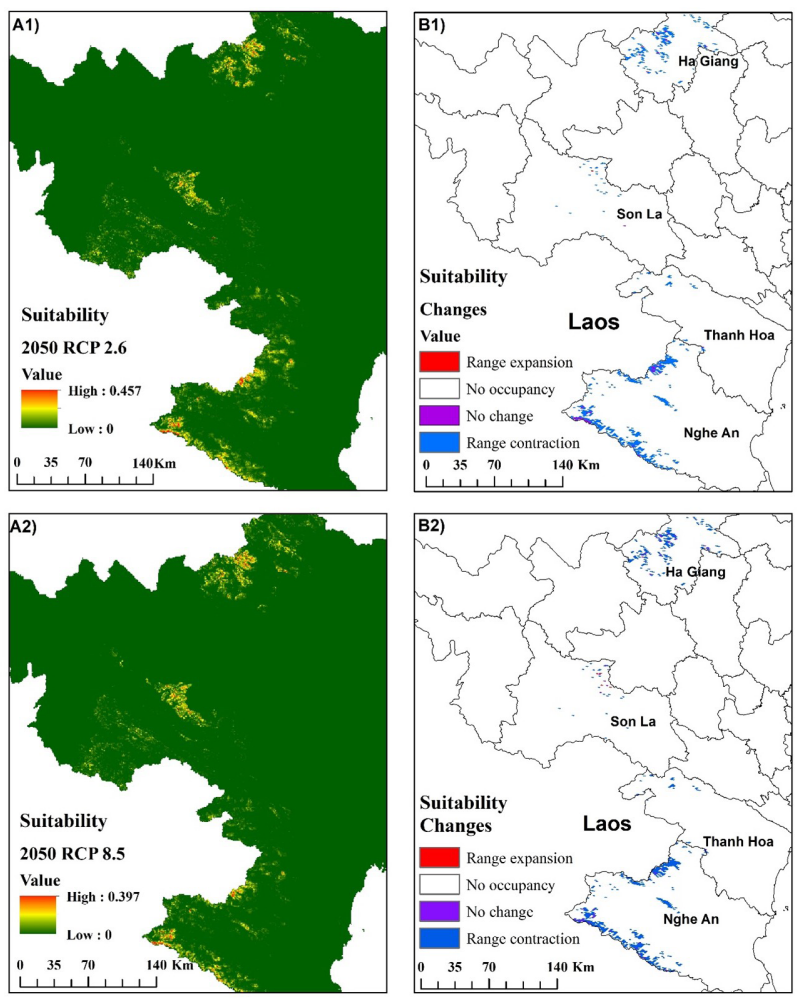

Figure 5: Environmental suitability maps for Cunninghamia konishii by 2050 A1) RCP 2.6, A2) RCP 8.5 and changes in potential geographical distribution of Cunninghamia konishii by 2050 B1) RCP 2.6 and B2) RCP 8.5

this research. The distribution centroid of the current habitat is located at $104.618 \mathrm{E}$ longitude and 20.376 $\mathrm{N}$ latitude in the western part of the Thanh Hoa province, in Vietnam. By 2050, the distribution centroid of the suitable future area would shift towards the southwest of Son La province under climate scenario RCP 4.5 and 8.5, and towards northwest of Thanh Hoa in the scenario RCP 2.6. In 2070, the distribution centroid of the suitable future area shifted towards the southern location. Considering scenarios RCP 4.5 and 8.5, the centroid of the suitable future area moved towards the boundary between the Son La and the Thanh Hoa provinces. While under RCP 2.6-2070s, the distribution centroid would shift Northwest, towards the border between the Nghe An province and Laos. One the one hand, the results indicated that the core distributional shift expressed a relatively high magnitude $(\sim 60 \mathrm{~km})$ towards the North when temperatures are high (RCP 4.5-2070s), and towards the South when temperatures are low (RCP 2.6-2070s), and it would readjust of about $45 \mathrm{~km}$ compared to the current distribution centroid. On the other hand, the distribution centroid towards the North, compared to the current centroid, was around $45 \mathrm{~km}$ under RCP
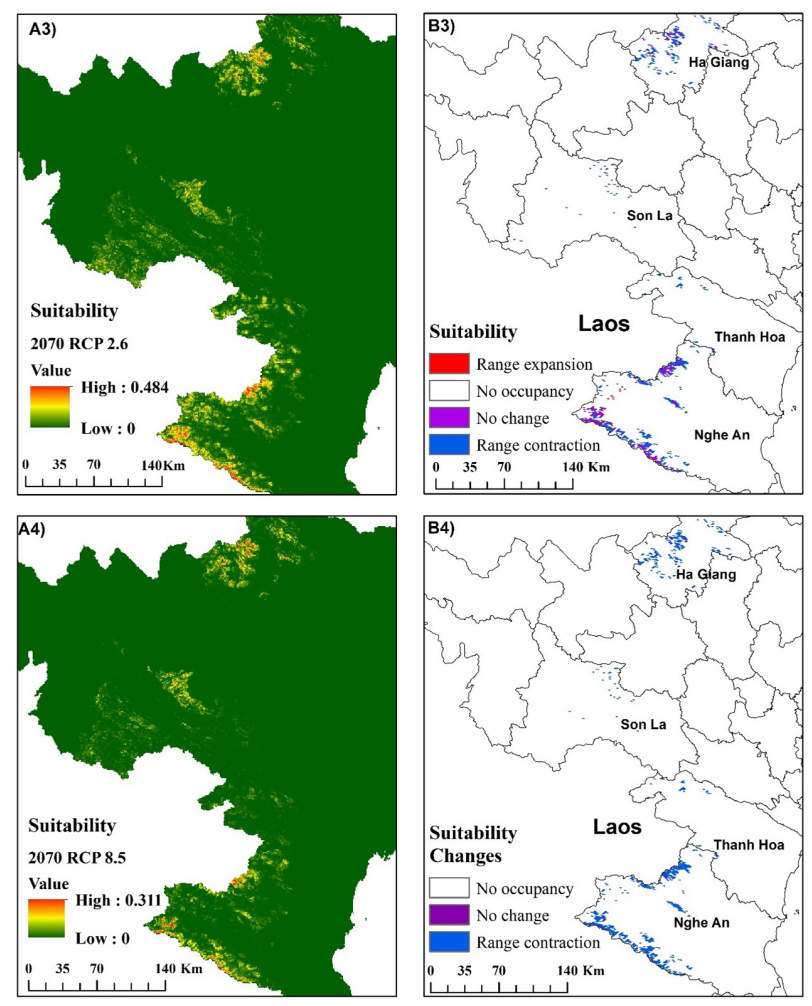

Figure 6: Environmental suitability maps for Cunninghamia konishii by 2070 A3) RCP 2.6, A4) RCP 8.5 and changes in potential geographical distribution of Cunninghamia konishii by 2050 B3) RCP 2.6 and B4) RCP 8.5

8.5-2070s. Global warming will induce some species to migrate to higher latitudes or higher elevations in order to resist to climatic changes (Zhang et al. 2018). Consistently, our prediction showed that climate change is shifting the distribution of $C$. konishii more towards the border between Vietnam and Lao PDR, nearby the Truong Son mountain which is located at a higher elevation.

\section{Conclusion}

It is concluded that species distribution modelling has been extensively used to guide forest management under the threat of future global climate change. This study represents the first mapping research of environmental and geographic distribution of C. konishii. According to our results and earlier biological information, we suggest that the distribution of C. konishii is mainly driven by the effects of topographical factors (elevation, slope), by land use, forest cover and soil type, by temperature annual range and temperature seasonality. Our results indicate that $C$. konishii growth is highly suitable in environments where we can find broadleaf forests and subtropical coniferous forests, growing at eleva- 
tions above $1000 \mathrm{~m}$ and featuring 15-25 degrees of slope. The suitability is particularly high where the soils are composed by humic Acrisols, humus yellow-red soil on granite, ferralic Acrisols and humus yellow-red soil on shale of Northern Vietnam. Under climate change scenarios, the habitat distribution of C. konishii would dramatically decline and the species would be forced to migrate to higher elevations, hence towards the border between Vietnam and Lao PDR. Finally, the results of this research can provide a theoretical reference for the promotion and plantations of $C$. konishii. The information on the medium and high-suitability areas distributed in the provinces of Ha Giang, Son La, Thanh Hoa and Nghe An, can be employed to undertake new conservation strategies for both the plantation of new forests, and for the protection of the germplasm resources for correct management of protected areas. Finally, it is suggested that future research works should be focused on setting protective forest belts around relatively stable distribution area in order to preserve the growth of C. konishii.

\section{ACKNOWLEDGEMENTS}

This research was supported by Vietnam-Russia Tropical Centre for project: "Application of Geographic Information Systems (GIS) method and molecular biology for investigation, monitoring and development Cunninghamia konishii Hayata species in Vietnam" in the period 2020 to 2022, project manager Mrs. Pham Mai Phuong.

\section{REFERENCES}

Asanok, L., Kamyo, T., Marod, D. (2020) Maximum entropy modeling for the conservation of hopea odorata in Riparian Forests. Central Thailand. Biodiversitas, 21(10), 4663-4670.

Badía, D., Ruiz, A., Girona, A., Martí, C., Casanova, J., Ibarra, P., and Zufiaurre, R. (2016) The influence of elevation on soil properties and forest litter in the Siliceous Moncayo Massif, SW Europe. Journal of Mountain Science, 13(12), 2155-2169.

Ban N.T., Ly, D.T., Tap, N., Dung, V. V., Thin, N.N., Tien, V.N., Khoi K.N. (2007) Vietnam Red Data Book Part II. Plants. Natural Sciences and Technology Publishers, Hanoi, pp.133.

Brown, J.L. (2014) SDM toolbox: a python-based GIS toolkit for landscape genetic, biogeographic and species distribution model analyses. Methods in Ecology and Evolution, 5, 694-700.
Chung, J. D., Chien, C. Te, Nigh, G., and Ying, C.C. (2009) Genetic variation in growth curve parameters of konishii fir (Cunninghamia lanceolata (lamb.) hook. var. konishii). Silvae Genet, 58(1-2), 1-10.

Chung, J.D., Lin, T.P., Tan, Y.C., Lin, M.Y., Hwang, S.Y. (2004) Genetic diversity and biogeography of Cunninghamia konishii (Cupressaceae), an island species in Taiwan: A comparison with Cunninghamia lanceolata, a mainland species in China. Molecular Phylogenetics and Evolution. Evol, 33(3), 791-801.

Dunckel, K., Weiskittel, A., Fiske, G., Sader, S.A., Latty, E., and Arnett, A. (2015) Linking remote sensing and various site factors for predicting the spatial distribution of eastern hemlock occurrence and relative basal area in Maine, USA. Forest Ecology and Management, 358, 180-191.

Elith, J., H. Graham, C., P. Anderson, R., Dudík, M., Ferrier, S., Guisan, A., J. Hijmans, R., Huettmann, F., R. Leathwick, J., Lehmann, A., Li, J., G. Lohmann, L., A. Loiselle, B., Manion, G., Moritz, C., Nakamura, M., Nakazawa, Y., McC. M. Overton, J., Townsend Peterson, A., J. Phillips, S., Richardson, K., Scachetti-Pereira, R., E. Schapire, R., Soberón, J., Williams, S., S. Wisz, M., E. Zimmermann, N. (2006) Novel methods improve prediction of species' distributions from occurrence data. Ecography, 29(2): 129-151.

Evcin, O., Kucuk, O., and Akturk, E. (2019) Habitat suitability model with maximum entropy approach for European roe deer (Capreolus capreolus) in the Black Sea Region. Environmental Monitoring and Assessment, 191(11),1-13.

Guo, Y., Li, X., Zhao, Z., Wei, H. (2018) Modeling the distribution of Populus euphratica in the Heihe River Basin, an inland river basin in an arid region of China. Science China Earth Sciences. 61, 1669-1684.

IUCN (2020) The IUCN Red List of Threatened Species. Retrieved 9 July 2020, from https://www.iucnredlist. org

Kamyo, T. \& Asanok, L. (2020) Modeling habitat suitability of Dipterocarpus alatus (Dipterocarpaceae) using MaxEnt along the Chao Phraya River in Central Thailand. Forest Science and Technology, 16, 1-7.

Kodrul, T., Gordenko, N., Sokolova, A., Maslova, N., Wu, X., Jin, J. (2018) A new Oligocene species of Cunninghamia R. Brown ex Richard et A. Richard (Cupressaceae) from the Maoming Basin, South China. Review of Palaeobotany and Palynology, 258, 234247.

Li, Y., Li, M., Li, C., Liu, Z. (2020) Optimized maxent model predictions of climate change impacts on the 
suitable distribution of Cunninghamia lanceolata in China. Forests, 11, 1-25

Lima-Ribeiro, M.S. (2015) EcoClimate: a database of climate data from multiple models for past, present, and future for macroecologists and biogeographers. Biodiversity Informatics, 10, 0-21

Loc, P.K., van The, P., Long, P.K., Regalado, J., Averyanov, L. V., Maslin, B. (2017) Native conifers of Vietnam - a review. Pakistan Journal of Botany, 49, 2037-2068.

Moustafa, A.A., Zaghloul, M.S., El-Wahab, R.H.A., Shaker, M. (2001) Evaluation of plant diversity and endemism in Saint Catherine Protectorate, South Sinai, Egypt. Egyptian Journal of Botany, 41, 121-139.

Ngoc, D. D. \& Quang, H.N. (2012) Chemical composition of the essential oil from woods of Cunningamia konishii Hayata from Ha Giang. Journal of Biology, 34, 469-472.

Ngoc, S.H. \& Thi,T.H.N. (2018) Study on the efects of sowing time to growth of Cunninghamia konishii Hayata seedlings in Hagiang province. Journal of Science and Technology, 177, 27-31.

Ngoc, S.H. \& Thi, T.N. (2017) Some physical characteristics of Cuninghamia konishii Hayata wood grown in Ha Giang province. Journal of Forestry Science and Technology, 1, 142-148.

Oke, O.A., Thompson, K.A. (2015) Distribution models for mountain plant species: The value of elevation. Ecological Modelling, 301, 72-77.

Pham, T. Van, Averyanov, L. V, Petersburg, S., Regalado, J., Nguyen, K.S., Resources, B. (2010) New data on the distribution and biology of Cunninghamia lanceolata var . konishii ( Hayata ) Fujita in Vietnam. Conference: In 2nd Symposium of the "Flore du Cambodge, du Laos et du Vietnam, Hanoi, Vietnam, 45-46

Pham, T.V., Nguyen, K.S., Resources, B., Averyanov, L.V., Petersburg, S. (2009) The diversity of the flora of Vietnam: Continuing contribution to the enumeration of conifer species, their distribution and assessment of their conservation value in Son La province. Journal of Genetics and Applications, 1, 43-49 (Vietnamese)

Pham, T.V., Nguyen, K.S., Resources, B., Averyanov, L.V., Petersburg, S., Regalado, J. (2007) The diversity of the flora of Vietnam 28. results of the inventory of conifer species and distribution and of the conservation value assessment in Ha Giang provice. Journal of Genetics and Applications, 3-4, 60-67 (Vietnamese)

Phillips, S.J., Anderson, R.P., Schapire, R.E. 2006. (2006) Maximum entropy modeling of species geographic distributions. Ecological Modelling, 190, 231-259.
Revadekar, J. V., Hameed, S., Collins, D., Manton, M., Sheikh, M., Borgaonkar, H.P., Kothawale, D.R., Adnan, M., Ahmed, A.U., Ashraf, J., Baidya, S., Islam, N., Jayasinghearachchi, D., Manzoor, N., Premalal, K.H.M.S., Shreshta, M.L. (2013) Impact of altitude and latitude on changes in temperature extremes over South Asia during 1971-2000. International Journal of Climatology, 33, 199-209.

Sau, L. (1996). Vietnam Forest Trees. Agricultural publishing house, Hanoi, Vietnam.

Sharma, S., Arunachalam, K., Bhavsar, D., Kala, R. (2018) Modeling habitat suitability of Perilla frutescens with MaxEnt in Uttarakhand-A conservation approach. Journal of Applied Research on Medicinal and Aromatic Plants, 10, 99-105.

Smith, C.D. (2008) The Relationship between Monthly Precipitation and Elevation in the Alberta Foothills during the Foothills Orographic Precipitation Experiment BT - Cold Region Atmospheric and Hydrologic Studies. The Mackenzie GEWEX Experience: Volume 1: Atmospheric Dyna. Edited by M. Woo. Springer Berlin Heidelberg, Berlin, Heidelberg, 167-185.

Thanh, T., Hieu, V., Sim, M.A., Dung, A., Thai, H., Thomas, H.H. (2017) The distribution and some ecological characteristics of Fokienia hodginsii (dunn) a. henry et thomas and Cunninghamia konishii hayata in Puhuong nature reserve, Nghean province. Journal of Biology, 39, 122-128.

Thi, N., Nga, T., Dung, N.A., Chung, N.T., Thai, T.H., Hung, N.D., Reserve, H.N., An, N., Resources, B., Noi, H. (2016) The distribution and some ecological characteristics, and essential oil of Cunninghamia konishii Hayata in $\mathrm{Pu}$ Hoat nature reserve, Nghe An province, Vietnam. Kku Engineering Journal, 43, 121-124

Thi, N., Nga, T., Dung, N.A., Thai, T.H. (2015) Composition of the root oil of Cunninghamia konishii Hayata growing wild in Nghe an province, Vietnam. The Seventh National Conference on Ecology and Biological Resources, Hanoi, Vietnam, 1340-1344.

Thuc, T., Van, T. N, Huong, H.T.L., Van, K. M., Hien, N.X., Phong, D.H. (2016) Climate change and sea level rise scenarios for Vietnam. Ministry of Natural Resources and Environment. Hanoi, Vietnam, 1-37.

Tran, H.T., Bazzali, O., Hoi, T.M., Minh, D.T., Thi, N., Nga, T., Tomi, F., Casanova, J., Bighelli, A. (2015) Chemical composition of the essential oil from Cunninghamia konishii Hayata growing wild in Vietnam. American Journal of Essential Oils and Natural Products, 2, 1-5. 
Tran, V.D., Vu, T.T., Tran, Q.B., Nguyen, T.H., Ta, T.N., Ha, T.M., Nguyen, H. V. (2018) Predicting suitable distribution for an endemic, rare and threatened species (Grey-shanked douc langur, pygathrix cinerea nadler, 1997) using MaxEnt model. Applied Ecology and Environmental Research, 16, 1275-1291.

Urbina-Cardona, N., Blair, M.E., Londoño, M.C., Loyola, R., Velásquez-Tibatá, J., Morales-Devia, H. (2019) Species Distribution Modeling in Latin America: A 25-Year Retrospective Review. Tropical Conservation Science, 12, 1-19

Wang, R., Li, Q., He, S., Liu, Y., Wang, M., Jiang, G. (2018) Modeling and mapping the current and future distribution of Pseudomonas syringae pv. actinidiae under climate change in China. PLoS ONE, 13, 1-21.
Woodwand, F.I. (1987) Climate and plant distribution. Cambridge University Press, Cambridge, UK.

Yang, X., Gao, Z., Zhou, T., Zhang, J., Wang, L., Xiao, L., Wu, H., Li, S. (2020) Mapping the potential distribution of major tick species in China. International Journal of Environmental Research and Public Health, 17, $1-15$.

Zhang, K., Yao, L., Meng, J., Tao, J. (2018), Maxent modeling for predicting the potential geographical distribution of two peony species under climate change. Science of the Total Environment, 634, 1326-1334. 


\begin{tabular}{|c|c|c|c|c|c|c|c|c|c|c|c|c|}
\hline & & & & & 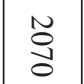 & & & & & & $\begin{array}{l}\text { No } \\
\text { y. }\end{array}$ & $\vec{\Xi}$ \\
\hline & $\ddot{i n}^{\infty}$ & & $\overrightarrow{i r}$ & & $\stackrel{N}{a}$ & & in & & $\overrightarrow{i n}$ & & $\stackrel{n}{a}$ & $\underset{\widetilde{\Omega}}{\pi}$ \\
\hline 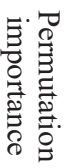 & 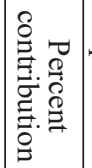 & 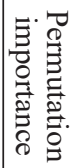 & 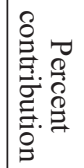 & 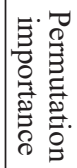 & 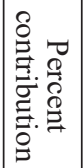 & 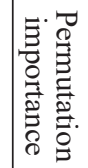 & 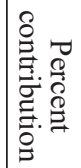 & 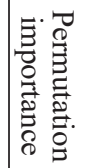 & 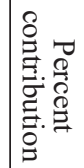 & 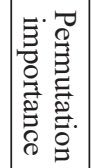 & 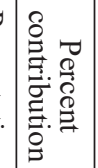 & $\begin{array}{l}\text { : } \\
\frac{\ddot{\sigma}}{\sigma} \\
\frac{\sigma}{\sigma}\end{array}$ \\
\hline$\stackrel{N}{\dot{u}_{1}}$ & $\begin{array}{l}\tilde{D} \\
\text { is }\end{array}$ & ñ & $\widehat{\sigma}$ & 岕 & w & E & $\tilde{\varepsilon}$ & $\hat{f}$ & u & w & un & 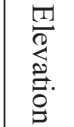 \\
\hline$\vec{u}$ & $\begin{array}{c}\infty \\
\infty\end{array}$ & 6 & $\bar{N}$ & $\tilde{N}$ & e & e & w & po & N & 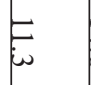 & $\stackrel{p}{\infty}$ & $\frac{\frac{\pi}{0}}{\frac{0}{0}}$ \\
\hline$\stackrel{N}{i}$ & $\vec{u}$ & $a$ & N & $\tilde{\sigma}$ & $E$ & $\bar{N}$ & E & e & 8 & $\vec{A}$ & $\hat{b}$ & $\begin{array}{l}\varpi \\
\stackrel{\varpi}{\circ} \\
\perp\end{array}$ \\
\hline$\stackrel{\bullet}{+}$ & $\begin{array}{c}\bar{a} \\
a\end{array}$ & 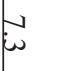 & $\ddot{\alpha}$ & $N$ & to & $\vec{b}$ & E & $\vec{b}$ & E & W & $E$ & 危 \\
\hline$\nu$ & $\stackrel{\sim}{\perp}$ & b & 6 & $\infty$ & $\omega_{1}$ & 6 & $\begin{array}{l}\infty \\
\infty \\
\infty\end{array}$ & $\bar{N}$ & ur & ${ }_{\infty}$ & $\stackrel{\infty}{\infty}$ & \begin{tabular}{ll}
0 & \multicolumn{1}{c}{} \\
0 & 0 \\
\hdashline & 0 \\
\hdashline & 0
\end{tabular} \\
\hline$\vec{i}$ & $\infty$ & ng & 而 & 5 & $\tilde{N}$ & n & i & ir & E & si & $\vec{b}$ & 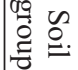 \\
\hline in & 6 & in & 6 & $N$ & b & i & 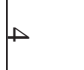 & e & W & e & ur & 苛. \\
\hline $\begin{array}{l}\bar{N} \\
i\end{array}$ & $\vec{\sigma}$ & a & 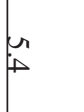 & 9 & h & b & 0 & po & 冓 & $N$ & $\overrightarrow{6}$ & 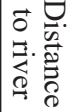 \\
\hline$\vec{u}$ & $\overrightarrow{6}$ & w & P & $\vec{\infty}$ & $\mu_{\mu}$ & e & $\mu$ & $\vec{t}$ & 6 & si & $\vec{s}$ & 苛 \\
\hline $\bar{u}$ & $\stackrel{\omega}{\sim}$ & in & 勾 & $\vec{\sigma}$ & 5 & $\vec{p}_{0}$ & po & 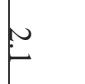 & 类 & w & 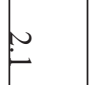 & $\begin{array}{l}\vec{b} \\
\stackrel{n}{0} \\
0 \\
\delta\end{array}$ \\
\hline$\dot{a}$ & $\stackrel{\odot}{\perp}$ & $\dot{v}$ & $\infty$ & 0 & po & $p$ & p & $E$ & 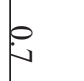 & e & 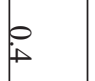 & $\frac{\frac{\varpi 0}{\circ}}{\frac{0}{N}}$ \\
\hline $\bar{i}$ & $\stackrel{\circ}{\perp}$ & 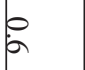 & 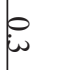 & $\stackrel{n}{n}$ & $e_{r}$ & w & e & V & - & s & e & 芯. \\
\hline i & 0 & 0 & ? & A & p & e & e & $\bar{N}$ & $e$ & i & 0 & $\begin{array}{l}\frac{\square}{\circ} \\
\frac{\infty}{\infty}\end{array}$ \\
\hline $\overrightarrow{i r}$ & : & e & 0 & b & e & $p$ & 0 & $p$ & e & ? & in & $\begin{array}{l}\frac{\square}{\circ} \\
\frac{0}{u}\end{array}$ \\
\hline $\overrightarrow{u r}$ & $: 0$ & b & 0 & 8 & e & $N$ & e & e & 0 & 8 & - & 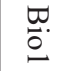 \\
\hline
\end{tabular}


Table S2. The probability presence of Cunninghamia konishii in relation to land use

\begin{tabular}{|c|c|c|c|c|c|}
\hline Rank & $\begin{array}{l}\text { Probability } \\
\text { presence }\end{array}$ & Land use & Rank & $\begin{array}{l}\text { Probability } \\
\text { presence }\end{array}$ & Land use \\
\hline 1 & 0.84 & $\begin{array}{l}\text { Rocky mountains in protection } \\
\text { forest area }\end{array}$ & 25 & 0.09 & Land used for sport \\
\hline 2 & 0.67 & Special-use forest & 26 & 0.09 & Urban \\
\hline 3 & 0.24 & Protection forest & 27 & 0.09 & Mineral land \\
\hline 4 & 0.17 & Unused mountainous land & 28 & 0.09 & $\begin{array}{l}\text { Land for production of } \\
\text { building materials }\end{array}$ \\
\hline 5 & 0.09 & Paddy land & 29 & 0.09 & Industrial land use \\
\hline 6 & 0.09 & Other annual crop land & 30 & 0.09 & Land for cultural facilities \\
\hline 7 & 0.09 & Cemetery & 31 & 0.09 & Historical sites Land \\
\hline 8 & 0.09 & Perennial crop land & 32 & 0.09 & Irrigation Land \\
\hline 9 & 0.09 & $\begin{array}{l}\text { Land for non-agricultural pro- } \\
\text { duction and business }\end{array}$ & 33 & 0.09 & Grass land used for livestock \\
\hline 10 & 0.09 & Water surface land for fishing & 34 & 0.09 & Annual crop flat land \\
\hline 11 & 0.09 & Homestead land & 35 & 0.09 & $\begin{array}{l}\text { Land for growing perennial } \\
\text { industrial crops }\end{array}$ \\
\hline 12 & 0.09 & Security land & 36 & 0.09 & Perennial crop land \\
\hline 13 & 0.09 & Upland rice & 37 & 0.09 & Others \\
\hline 14 & 0.09 & $\begin{array}{l}\text { Rivers and specialized water } \\
\text { surfaces }\end{array}$ & 38 & 0.09 & Land for perennial fruit trees \\
\hline 15 & 0.09 & Annual crop Upland 1 & 39 & 0.09 & Medical facility land \\
\hline 16 & 0.09 & Defence land & 40 & 0.08 & Forest plantation land \\
\hline 17 & 0.09 & Land of transport & 41 & 0.00 & Landfill \\
\hline 18 & 0.09 & Other Paddy land & 42 & 0.00 & Land used for science \\
\hline 19 & 0.09 & Unused flat land & 43 & 0.00 & Scenic land \\
\hline 20 & 0.09 & Annual crop land & 44 & 0.00 & Land with diplomatic \\
\hline 21 & 0.09 & Other agricultural land & 45 & 0.00 & $\begin{array}{l}\text { Commercial and services } \\
\text { Land }\end{array}$ \\
\hline 22 & 0.09 & Aquaculture Land & 46 & 0.00 & Land for energy production \\
\hline 23 & 0.09 & Specially used water land & 47 & 0.00 & Land for state offices \\
\hline 24 & 0.09 & Land for production and business & 48 & 0.00 & Market land \\
\hline
\end{tabular}


Table S3. The probability presence of Cunninghamia konishii in relation to soil groups

\begin{tabular}{|c|c|c|c|c|c|}
\hline Rank & Soil type* & Probability presence & Rank & Soil type* & Probability presence \\
\hline 1 & A & 0.73 & 26 & RK & 0.05 \\
\hline 2 & $\mathrm{Ha}$ & 0.63 & 27 & E & 0.05 \\
\hline 3 & $\mathrm{Hq}$ & 0.59 & 28 & $\mathrm{C}$ & 0.05 \\
\hline 4 & Hs & 0.42 & 29 & M & 0.05 \\
\hline 5 & $\mathrm{Fa}$ & 0.11 & 30 & $B$ & 0.05 \\
\hline 6 & $\mathrm{Fq}$ & 0.09 & 31 & $\mathrm{Pj}$ & 0.05 \\
\hline 7 & River & 0.05 & 32 & $\mathrm{Pg}$ & 0.05 \\
\hline 8 & Rock & 0.05 & 33 & $\mathrm{Mi}$ & 0.05 \\
\hline 9 & $\mathrm{Hv}$ & 0.05 & 34 & $\mathrm{Mn}$ & 0.05 \\
\hline 10 & FL & 0.05 & 35 & $\mathrm{Cc}$ & 0.05 \\
\hline 11 & Fs & 0.05 & 36 & SM & 0.05 \\
\hline 12 & $\mathrm{Hk}$ & 0.05 & 37 & $\mathrm{Fu}$ & 0.05 \\
\hline 13 & Py & 0.05 & 38 & $\mathrm{Ru}$ & 0.05 \\
\hline 14 & $\mathrm{Fv}$ & 0.05 & 39 & $\mathrm{Fe}$ & 0.05 \\
\hline 15 & $\mathrm{D}$ & 0.05 & 40 & py & 0.05 \\
\hline 16 & $\mathrm{Rv}$ & 0.05 & 41 & fs & 0.05 \\
\hline 17 & $\mathrm{Rdv}$ & 0.05 & 42 & $\mathrm{Pc}$ & 0.05 \\
\hline 18 & P & 0.05 & 43 & pc & 0.05 \\
\hline 19 & Fk & 0.05 & 44 & $\mathrm{Rr}$ & 0.05 \\
\hline 20 & $\mathrm{Fj}$ & 0.05 & 45 & $\mathrm{fk}$ & 0.05 \\
\hline 21 & Ep & 0.05 & 46 & a & 0.05 \\
\hline 22 & $\mathrm{~Pb}$ & 0.05 & 47 & $\mathrm{Ba}$ & 0.05 \\
\hline 23 & Pf & 0.05 & 48 & $\mathrm{Nu}$ & 0.05 \\
\hline 24 & $\mathrm{bb}$ & 0.05 & 49 & others & 0.05 \\
\hline 25 & $\mathrm{Fl}$ & 0.05 & 50 & SON & 0.05 \\
\hline
\end{tabular}

*Soil classification according to the National Classification System 


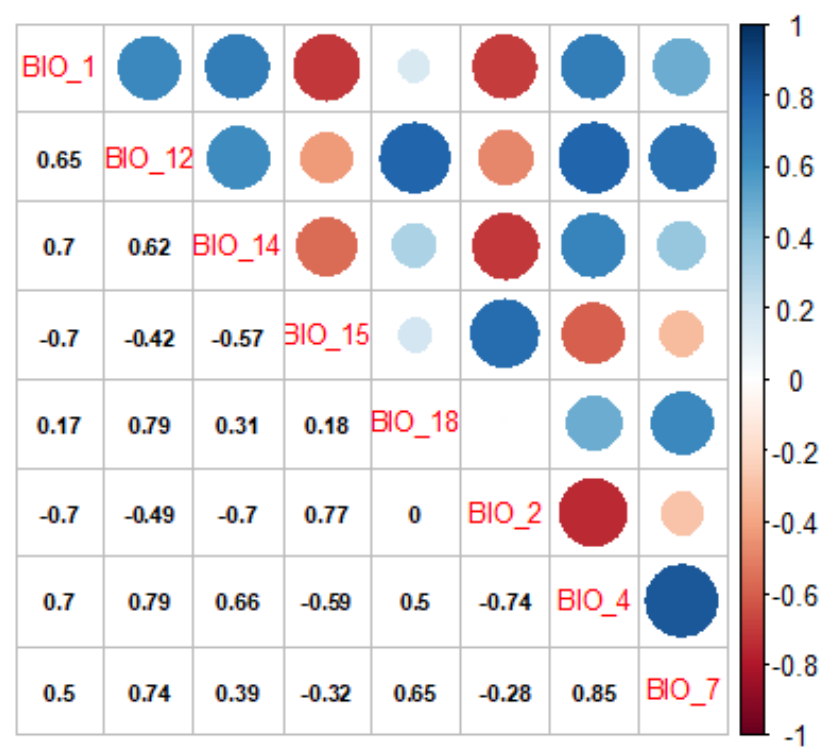

Fig.S.1. Correlation matrix among bioclimatic variables

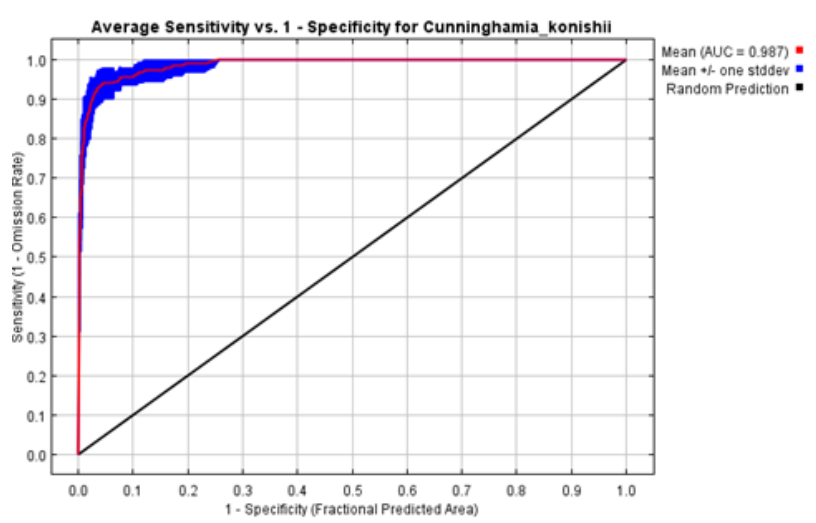

Fig S.2. ROC curve and AUC value under the current period (10 replicated runs). The current period was from 1950 to 2000

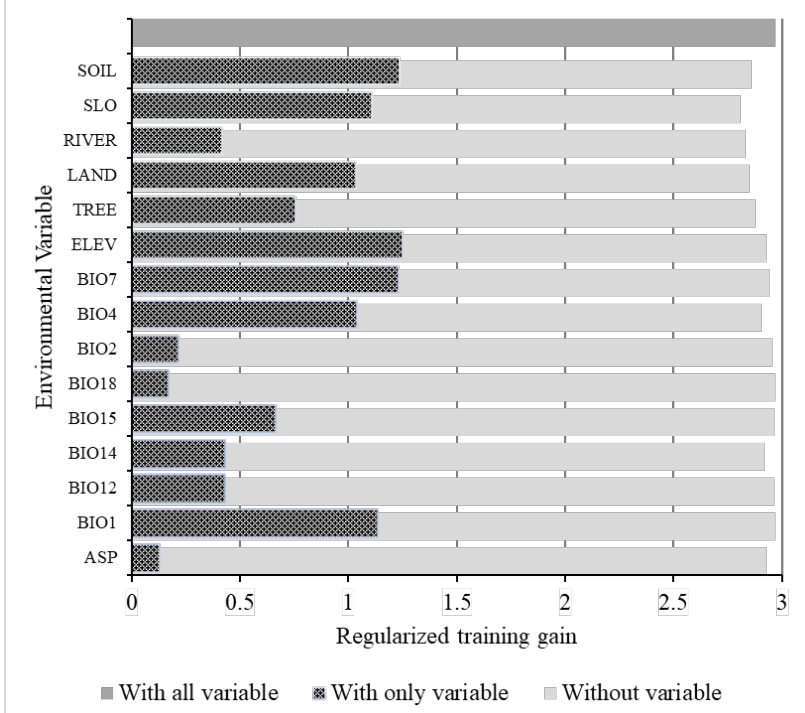

Fig S.3. Relative predictive power of different environmental variables based on the jackknife of regularized training gain in MaxEnt models for Cunninghamia konishii Hayata 

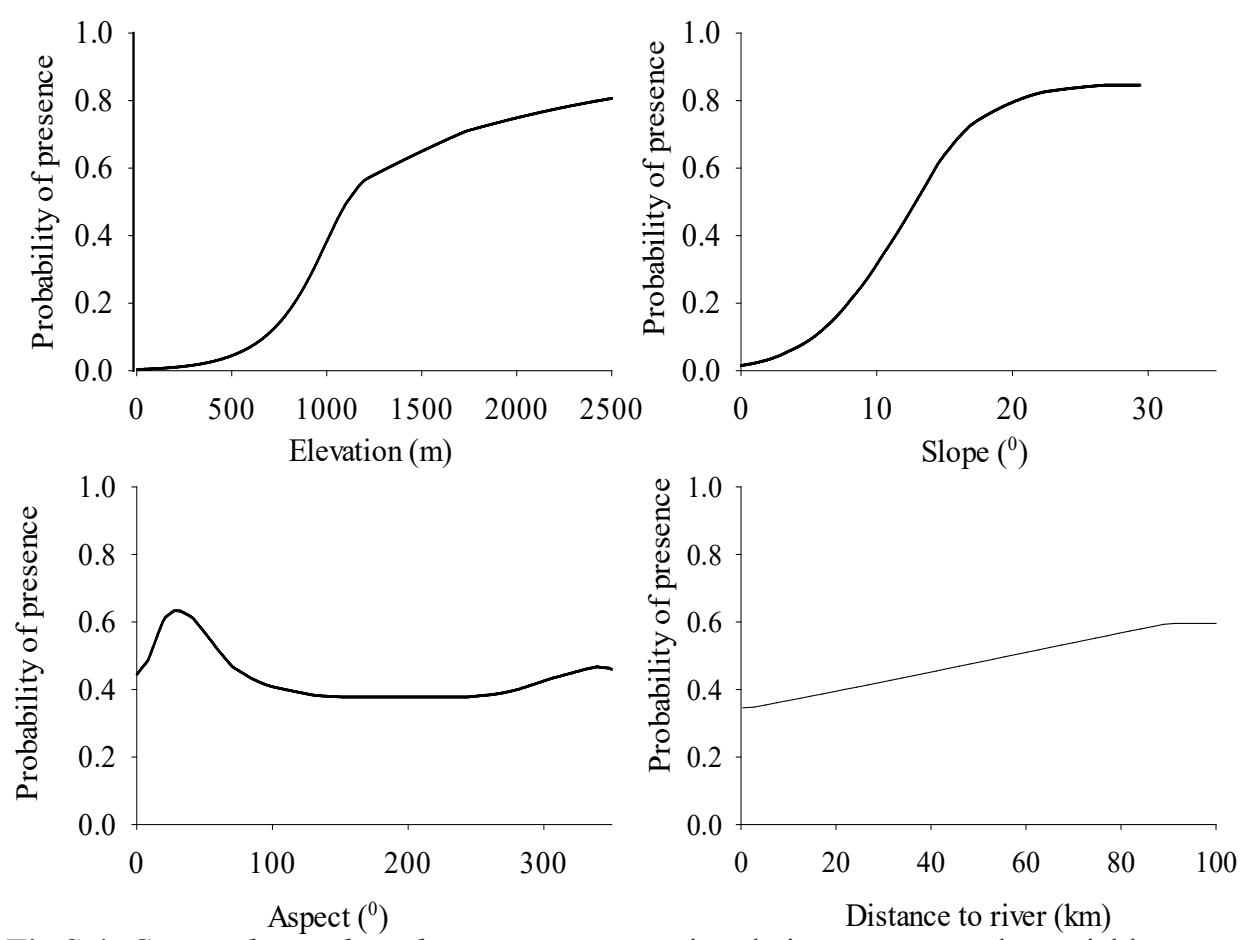

Fig.S.4. Cunninghamia konishii response curves in relation to topography variables
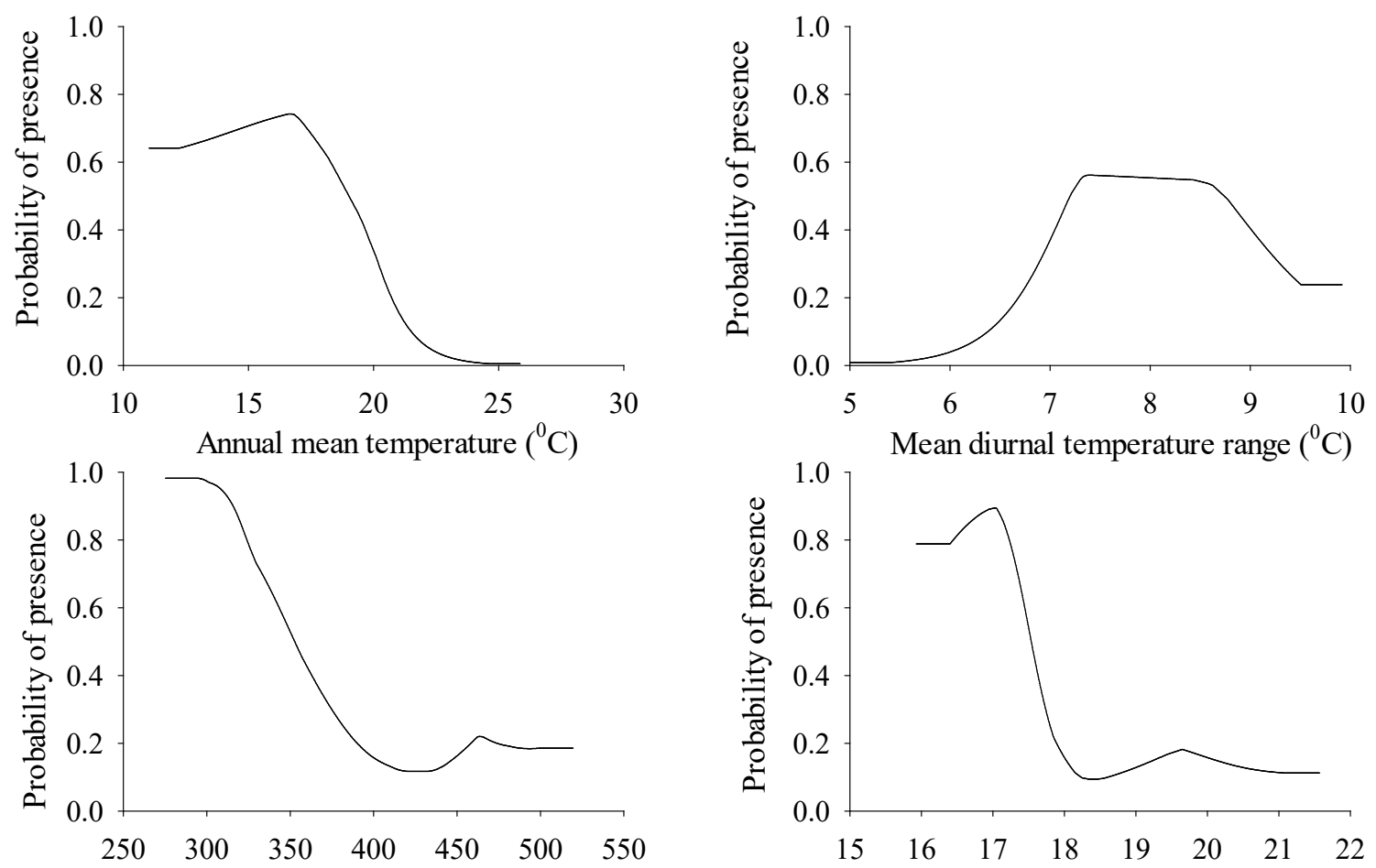

Temperature seasonality

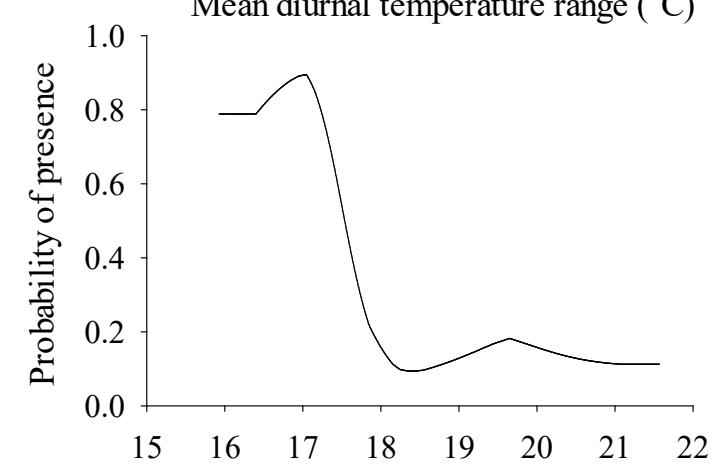

Temperature annual range $\left({ }^{0} \mathrm{C}\right)$

Fig S.5. Cunninghamia konishii response curves in relation to temperature variables 

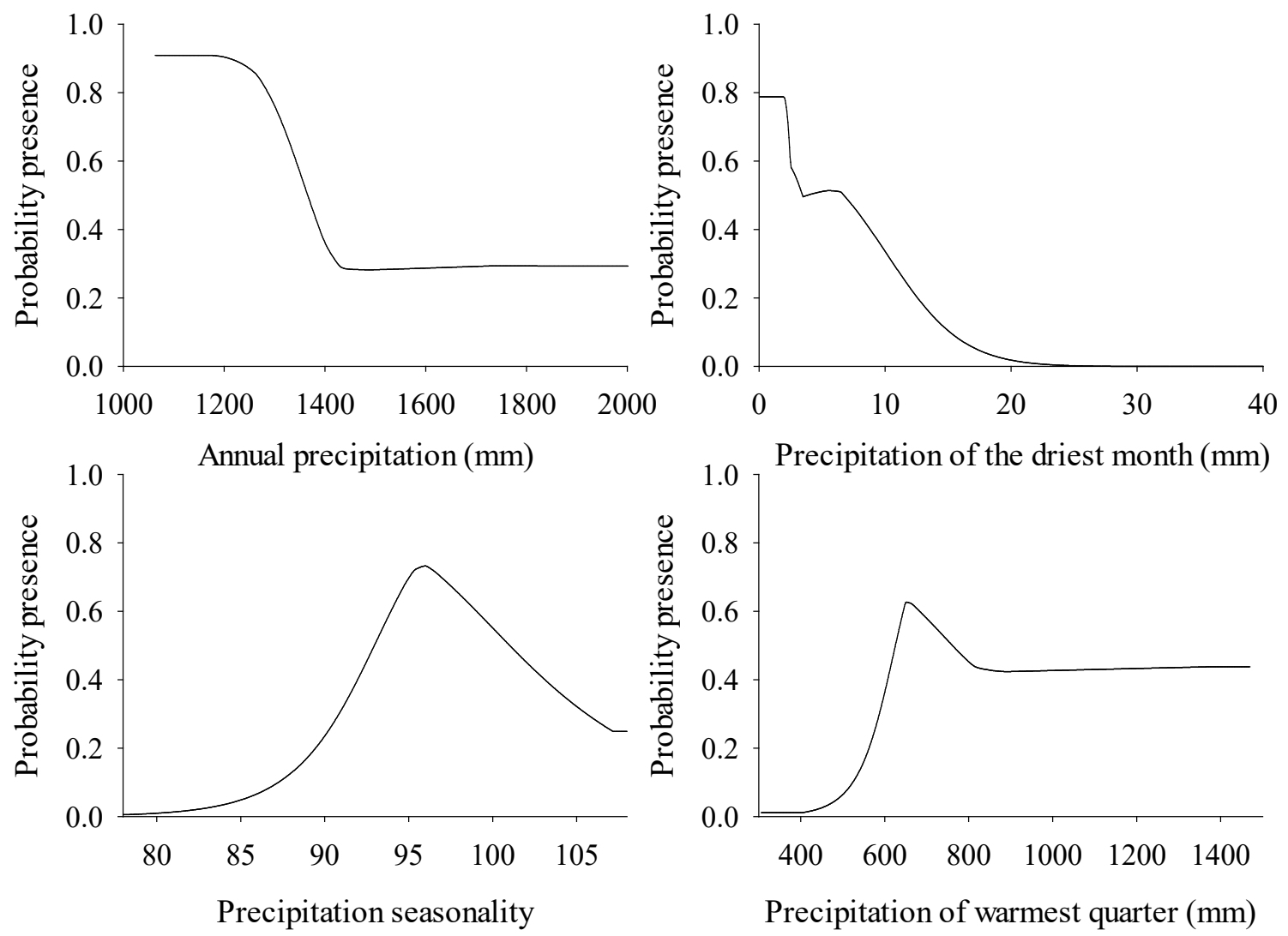

Fig S.6. Cunninghamia konishii response curves in relation to precipitation variables

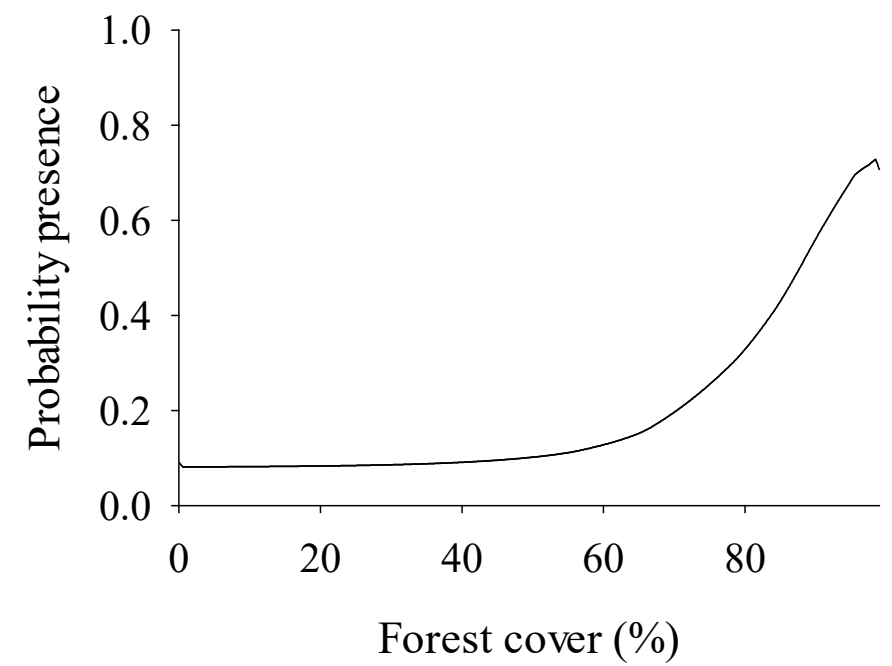

Fig S.7. Cunninghamia konishii response curves in relation to forest cover 